\title{
Risperidone Formulation in Rumenic Acid
}

National Cancer Institute

\section{Source}

National Cancer Institute. Risperidone Formulation in Rumenic Acid. NCI Thesaurus. Code C131306.

An orally bioavailable capsule formulation containing the antipsychotic agent risperidone suspended in the lipid rumenic acid, with potential antineoplastic activity. Upon administration of VAL401, risperidone may, through an as of yet not elucidated mechanism of action, reduce cellular activity and tumor cell proliferation in multiple cancers. 